\title{
CNRS reform will boost strategic advice
}

[PARIS] The administrative council of France's Centre National de la Recherche Scientifique (CNRS), Europe's largest fundamental research agency, meets today (25 June) to suggest reforms that would reinforce the input of independent advice on scientific strategy at every level of CNRS management.

One key issue is the large role of the CNRS's national committee in setting overall research strategy. The committee is a significant body in French science, evaluating laboratories and administering recruitment not only within CNRS's own laboratories but also in CNRS laboratories attached to universities. Reforms to the committee will affect 80,000 staff.

The national committee has some $40 \mathrm{sec}-$ tions, each consisting of scientists from the research agencies and universities. According to one CNRS administrative council member, individual sections tend to support their own subdisciplines, rather than adopting a broader view of strategic needs.

"If you ask the laser physics community, of course they will say we need more research on lasers in France, but what we need to know is whether the entire physics community thinks this is the case," he says.

To remedy this, the council is likely to propose that, while the number of sections should not be drastically reduced for the purpose of day-to-day evaluation, there should be a major regrouping of sections when this is required to give a broader view of strategic issues.

Earlier proposed reforms of the national committee have met with resistance from researchers. A recent survey of all CNRS researchers by the administrative council showed that a large majority opposed a proposal by Claude Allègre, the minister for national education, research and technology, to halve the number of sections (see Nature 393, 506; 1998).

But Catherine Brèchignac, the CNRS director-general, is one of several administrators who believe the conflict over the number of scetions has distracted attention from the more pressing issue of determining the committee's role in setting scientific strategy. She feels that the furore over the issue has triggered resistance among researchers that threatens to block more important reforms.

Another proposed change intended to reduce the power of individual sections is the complete remodelling of the councils that advise the CNRS's seven departments. At present these are made up of representatives of the sections of the national committee.

The council is expected to propose that each department should have an independent scientific board consisting of directly elected researchers, nominated members and foreign scientists.

The recent consultation showed that a narrow majority of CNRS scientists - 54 per cent - agreed that the departments should play a larger role in setting strategy. A further 30 per cent who opposed this said they would accept it if assurances were given that the departments would base their strategic thinking on that of the national committee.

CNRS researchers' attachment to the national committee stems from the fact that two-thirds of its members are elected directly by the scientific community. But, as one council member points out, there seems no reason why researchers should not also accept separate departmental advisory committees, given that these would also include a large proportion of directly elected researchers.

Prospects for the proposed reforms seem to be improved by the fact that their broad thrust is supported by both Brèchignac and Edouard Brezin, the president of the administrative council, who have often clashed in the past over the content and pace of reforms.

The director-general's office is likely to see similar reforms. It has an advisory board of three ministry representatives and the

heads of the CNRS's seven departments, and is chaired by the director-general. Many believe this is an incestuous set-up and that a separate body, again including a significant number of international experts, is needed.

"The danger of the current set-up is that CNRS could be seen as just made up of seven independent departments, whereas it is supposed to take strategic decisions of national significance," says one CNRS official.

Under the reform proposals, the council itself would have a much greater role, being involved from the outset in preparing reforms and decisions. Although the board votes on the budget and other strategic issues, at present its role is largely restricted to rubber-stamping proposals from the director-general.

"This creates a situation where if, say, a proposal for genome strategy reaches us and we are unhappy with it, at present we only have two choices: accept it, or reject it, and provoke a crisis by setting back what has often been protracted negotiations among the various partners," says a CNRS council member. "We need to be involved from the outset to ensure that the director-general and the council have a parallel vision of the directions being taken."

DeclanButler

\section{Ozone recovery will be long-term affair}

[LONDON] Although the full recovery of the Earth's ozone shield is expected to occur by the middle of the next century, signs of the recovery may not become apparent for another two decades. That is the conclusion of the latest four-yearly ozone assessment published this week by the World Meteorological Organization (WMO) and the United Nations Environment Programme (UNEP).

Godwin Obasi, secretary-general of the WMO, said the report, prepared by more than 200 scientists from around the world, showed that the 1987 Montreal protocol to phase out ozone-depleting substances is clearly working.

"The WMO global network of stations is detecting lower rates of increase in bromine and a decline in chlorine concentrations in the troposphere," Obasi said. But he added: "It might not be possible to detect firm signs of ozone recovery before another 20 years due to natural atmospheric and ozone variability."

Klaus Töpfer, executive director of UNEP, said the world owed scientists "a debt of gratitude" for their "unbiased advice", and for showing governments an "effective path to save the ozone layer". But he added that a complete recovery of ozone levels will need complete compliance with the

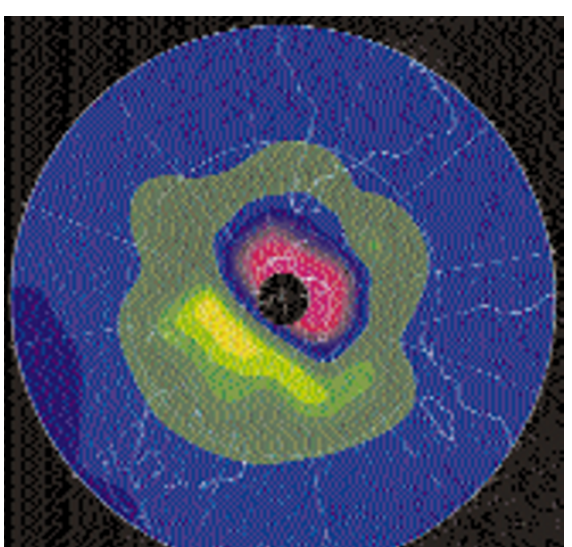

Still growing: the ozone hole is as big as ever in this view of the South Pole in October 1997.

protocol, particularly from developing countries.

Under the terms of the Montreal protocol, these countries must complete the phasing out of ozone-depleting chemicals by 2005. They are due to start next year. But emissions from India and China have exceeded earlier projections.

Developing countries have access to a global fund - the Montreal Multilateral Fund - to help them make the transition to using and producing alternatives to ozonedepleting chemicals.

Ehsan Masood 